\title{
A CERTIFICAÇÃO ISO 14001 E O ENDIVIDAMENTO DAS EMPRESAS BRASILEIRAS
}

\author{
Enezio Mariano da Costa' \\ Valcemiro Nossa² \\ Silvania Neris $\mathrm{Nossa}^{3}$ \\ Vania Maria da Costa Borgerth ${ }^{4}$
}

Resumo: A certificação ISO 14001 compreende um conjunto de normas ambientais para alcançar a responsabilidade ambiental, aumentando a competitividade das Companhias no mercado nacional e internacional. Assim, esta pesquisa tem por objetivo verificar a relação da implantação do sistema de gestão ambiental (SGA) - ISO 14001 com o endividamento das empresas brasileiras listadas na B3. Para mensurar esse efeito foi utilizada a análise de regressão em painel com estimação dif-in-dif e o teste de média para duas populações. A fonte dos dados se refere às demonstrações financeiras das empresas listadas na B3, disponibilizadas pela Economática e informações sobre as certificações disponíveis nos sites das empresas referente ao período de 1996 a 2016. Os resultados encontrados apontam evidências de que a certificação ISO 14001 afeta o endividamento de longo prazo de forma positiva e o de curto prazo de forma negativa, ou seja, as empresas com certificação ISO 14001 estão substituindo financiamento de curto por financiamento de longo prazo. Este pode ser resultado de um aumento de confiança devido ao compliance trazido pela certificação ISO 14001.

Keywords: Certificação; ISO 14001; Endividamento; B3; Conformidade.

' eneziocon@gmail.com - Fucape Business School. Vitória-ES. Brasil. https://orcid.org/0000-0001-8473-7613

${ }^{2}$ valcemiro@fucape.br - Fucape Business School. Vitória-ES. Brasil. https://orcid.org/0000-0001-8091-2744

3 silvanianossa@fucape.br - Fucape Business School. Vitória-ES. Brasil. https://orcid.org/0000-0001-8087-109X

${ }^{4}$ vborgerth@gmail.com - Fucape Business School. Vitória-ES. Brasil. https://orcid.org/0000-0001-6366-6123 


\title{
THE ISO 14001 CERTIFICATION AND THE INDEBTEDNESS OF THE BRAZILIAN COMPANIES
}

\begin{abstract}
The ISO 14001 certification comprises a set of environmental standards to achieve environmental responsibility, increasing the companies' competitiveness in the domestic and international markets. The aim of this research is to verify the relationship between the implementation of the environmental management system (EMS) - ISO 14001 and the indebtedness of the Brazilian companies listed in B3. To measure this effect, panel regression analysis with dif-in-dif estimation and the mean test for two populations were used. The data source refers to the financial statements of the companies listed in B3, using Economática and information on the certifications available on the companies' websites for the period from 1996 to 2016. The results show evidence that ISO 14001 certification affects long-term debt positively and short-term debt negatively, meaning that companies with ISO 14001 certification are replacing short-term financing with long-term financing. This may be a result of increased confidence due to compliance by ISO 14001 certification.
\end{abstract}

Keywords: Certification; ISO 14001; debt; B3; Compliance 


\section{INTRODUÇÃO}

$A^{t}$ temática deste artigo trata-se de uma análise das abordagens feitas sobre a relação do sistema de gestão ambiental (SGA). Assim, estuda-se a relação da certificação ISO 14001 com o endividamento das empresas brasileiras. A preocupação com os riscos e danos ao meio ambiente fez com que as empresas adotassem uma política de controle de gestão para reduzir os impactos ambientais, por meio da preservação ambiental. Essa redução de impactos ambientais tem o intuito de satisfazer os seus clientes, aumentando o retorno esperado da empresa pela redução de processos judiciais e melhoria da eficiência das operações, captação de novos clientes e mercados, além da responsabilidade com o desenvolvimento sustentável (França et al., 2015).

Este contexto leva as empresas a estabelecer um sistema de gerenciamento ambiental, buscando alcançar o equilíbrio entre a proteção ambiental e as necessidades socioeconômicas. A certificação ISO (International Organization for Standardization). A certificação ISO 14001 compreende um conjunto de normas ambientais internacionais que é vista como umas das soluções para alcançar a responsabilidade ambiental, melhorando assim perspectivas de sobrevivência das empresas no curto e longo prazo (Chritmamm, 2000; Rao \& Holt, 2005; Shan, You, Wang, \& Liu, 2015).

A implantação do SGA nas empresas por meio da certificação ISO 14001, pode ser fundamental para aumentar a competitividade das empresas no mercado nacional e internacional, mas é um processo que incorre em custo e tempo para a sua implementação. E este contexto pode ser um obstáculo para as empresas, em consequência das restrições orçamentárias das empresas. Para a obtenção de crédito, dentre os problemas enfrentados pelas empresas brasileiras no período analisado nesta pesquisa, destacam-se as altas taxas de juros, o processo burocrático na obtenção de recursos financeiros e as crises financeiras (Santos \& Seiffert, 2006, Damasceno, 2019).

Segundo Alberton e Costa Jr. (2007) os investimentos para implantação do SGA ocorrem no intuito de mitigar impactos ambientais de determinadas atividades. Tais investimentospodem afetar os indicadores financeiros das organizações, Cellier e Chollet (2016), Barros, Silva e Voese (2015) e Song, Zhao e Zeng (2017) argumentam que o investimento em SGA pode elevar o desempenho econômico das empresas No que se refere à captação de recursos por meio de empréstimo a certificação pode proporcionar compliance para as empresas certificadas e este pode ser um diferencial destas em relação às empresas que não têm certificação.

O investimento em SGA pode trazer para a empresa um diferencial frente aos investidores e os analistas financeiros com relação aos fatores de Responsabilidade Ambiental que podem ser levados em consideração no momento de uma empresa buscar crédito (Sharfman \& Fernando, 2008; Matuszak-Flejszman 2009; El Ghoul El Ghoul, Guedhami, Kwok, \& Mishra, 2011; Ferron, Funchal, Nossa, \& Teixeira, 2012; Zhu, Cordeiro, Sarkis., 2013; Cellier \& Chollet, 2016; Erragragui, 2017).

Dentre os itens que podem ser levados em consideração para a obtenção destacam-se o risco observado por meio das demonstrações financeiras e o risco ambiental (Mengze \& Wei 2015; Vasi \& King 2012; Erragragui, 2017). O não investimento em um SGA pode reduzir a rentabilidade das empresas, bem como seu fluxo de caixa podendo, inclusive, comprometer a capacidade de pagamento dos empréstimos pelas empresas e isto poderia afetar a estratégia das empresas sobre a forma de captação de recursos de curso/longo prazo (Stefan \& Paul, 2008; Heras-Saizarbitoria, Molina-Azorín, \& Dick, 2011). 
Nesse sentido, para que as empresas possam programar o seu SGA, bem como para desenvolver e ampliar suas atividades, a partir da execução de projetos de implantação e expansão de suas operações, há a necessidade da obtenção de recursos financeiros e quando estes recursos financeiros são provenientes de capitais de terceiros, a empresa assume dívidas (Vieira Filho, 2015). Os períodos de crise financeira podem afetar as taxas de juros assumidas pelas empresas em contratos (Damasceno, 2019).

Nunes (1997), Oliveira (2011), Gibson e Tierney (2011), Santos e Seiffert (2006) afirmam que além das questões associadas à burocracia e regulamentação ambiental, os altos custos de implantação do SGA, bem como as restrições de mercados de crédito são entraves em países emergentes para que as empresas adotem sistemas de gestão. No entanto, não há evidência se de fato a certificação ambiental é positivamente relacionada ao aumentoda dívida das organizações.

Estudar este tema no mercado brasileiro se justifica, primeiro porque o tema ainda não foi observado empiricamente no mercado brasileiro, segundo porque o mercado brasileiro passou por um período de poucos lançamentos de ações, inclusive, devido ao período de crise que perpassa o período estudado e por último por que o Brasil é um mercado representativo em relação aos demais países da América Latina.

Ao analisar esses fatores, a pesquisa se propôs a responder a seguinte questão: o compliance, representado pela certificação ISO 14001, influência no endividamento das empresas listadas na Bolsa de Valores - B3? O objetivo deste estudo foi verificar o efeito da implantação do SGA, por meio da certificação ISO 14001, no endividamento das empresas brasileiras com ações negociadas na B3. O endividamento é analisado separadamente: primeiramente estima-se a relação estudada com o endividamento total como variável explicada, na sequência o endividamento de curto prazo e por último o endividamento de longo prazo é a variável explicada.

Esta pesquisa se justifica também pela: preocupação da sociedade com as questões ambientais (Faroni, Silveira, Magalhães, \& Magalhães, 2010); a necessidade de investimentos e dos altos custo da implantação do SGA (Alberto \& Costa (2007); a relação de endividamento das empresas na obtenção de recursos por conta da certificação (Vieira Filho, 2015); e a tendência mundial em relação aos investidores, que procuram empresas socialmente responsáveis, sustentáveis e rentáveis para aplicar os seus recursos (BMF\&BOVESPA, 2017). Empresas com mais compliance podem estar atraindo a atenção dos fornecedores de capital mais do que empresas que não investem em SGA.

A contribuição deste estudo, na prática, é suscitar por meio desta pesquisa elementos que possam ser utilizados para debates futuros em relação à responsabilidade social corporativa. Pretende-se verificar se a certificação ISO 14001, pode ser utilizada como um sinalizador de compliance e isto ajudar na captação de recursos financeiros. Adicionalmente pretende-se verificar os efeitos do SGA não somente no endividamento geral, mas também no endividamento das empresas no curto e no longo prazo.

Trata-se este estudo de uma pesquisa empírica que se utilizou de dados disponíveis na Economática e no site das empresas analisadas, referente ao período de 1996 a 2016. A estimação da relação estudada ocorreu por meio de uma análise de regressão em painel com estimação dif-in-dif e o teste de média para duas populações. Os resultados encontrados apontam que existe uma maior evidência da norma afetar o endividamento de longo prazo de forma positiva e o de curto prazo de forma negativa. $\mathrm{O}$ aumento de dívida de longo prazo e redução de dívida de curto prazo é visto positivamente pela literatura de finanças. E este pode ser resultado de um aumento de confiança devido à adesão da norma, que trouxe mais compliance, menos risco, melhor sinalização para as empresas com certificação ISO 14001. 


\section{REFERENCIAL TEÓRICO}

Para Dal Magro, Di Domenico, Utzig, Lavarda e Mazzioni (2012) a globalização e os avanços tecnológicos trazem constantes desafios para as empresas E diante da competitividade global, vem a necessidade de aprimoramento nos processos produtivos frente aos consumidores cada vez mais exigentes (Dal Magro et al., 2012). Segundo Moura, Nascimento e Luca (2010) as empresas interessadas em expandir seus negócios atraem investidores e aumentam a confiabilidade junto aos mercados. Inclusive, algumas empresas passaram a divulgar informações adicionais relacionadas à gestão empresarial, mostrando suas ações de responsabilidade social e ambiental, indo além das exigências legais (Moura et al., 2010).

Nesse sentido, a responsabilidade social corporativa - RSC tem como principal característica a coerência ética nas práticas e no atendimento das exigências que a sociedade impõe nas relações com seus diversos públicos, demonstrando transparência das ações sociais e as contribuições para o desenvolvimento da sociedade (Dal Magro et al., 2012). De acordo com Mazzioni, Tinoco e Oliveira (2007), se faz necessário assumir uma postura proativa na implementação de ações que visam à solução dos problemas sociais.

Oliveira e Pinheiro (2009) afirmam que em relação às empresas a RSC está associada às estratégias de sustentabilidade de longo prazo das empresas. Os autores destacam ainda que ao ampliar os negócios no âmbito internacionalas empresas são exigidas a adotar práticas modernas de gestão que demonstrem a preocupação com os efeitos sociais e ambientais da atividade desenvolvida, tornando-se assim, um diferencial competitivo. Em outras palavras a certificação pode proporcionar compliance para as empresas certificadas.

Diante desses desafios que foram impostos em decorrência do crescimento econômico mundial, as empresas passam por exigências do mercado cada vez mais competitivo, com isso as empresas buscam novas formas de desenvolvimento social, econômico e de preservação ambiental, sem redução de recursos naturais e sem danos ao meio ambiente (Barbosa, 2008). Tais práticas impulsionaram a criação de normas que possibilitassem o desenvolvimento de forma sustentável (Barbosa, 2008).

Lemer (2015) destaca que em 1996 apoiada pelas manifestações que eclodiram com o despertar da consciência ecológica influenciada pelas discussões levantadas na ECO-92, e surgiram então as primeiras normas da série ISO, direcionada pelo Sistema de Gestão Ambiental. Para Ramos, Álvares, Souza e Pereira (2006), a importância da criação da norma ISO foi no sentido de definir critérios e exigências de procedimentos de gestão ambiental padronizadas no âmbito nacional, levando em conta os requisitos legais e as informações de impactos ambientais significativos. Sobre esses aspectos Lemer (2015) destacam que estas normas oferecem confiança aos seus clientes, fornecedores e demais partes interessadas, uma vez que o mercado nacional e internacional exerce pressão para receber produtos resultantes de ações ecologicamente corretas. E neste sentido a conformidade proporcionada pela certificação pode reduzir riscos e emitir sinais de maior reputação aos fornecedores de recursos.

Para Hikichi, Salgado e Beijo (2016), a adesão à ISO 14001 é obtida de forma voluntária. Ou seja, não há um dispositivo legal para a certificação, porém ela geralmente proporciona inúmeros benefícios tangíveis (relacionados a ganhos econômicos) e intangíveis (relacionados a melhoria na reputação ambiental) para as empresas certificadas. A vantagem em possuir o certificado é demonstrar publicamente aos clientes, fornecedores e demais interessados, um SGA por meio de padrões reconhecidos nas esferas nacional e internacional tornando-se assim, mais competitiva no mercado nacional e internacional (Mo- 
reira, 2006; Pombo \& Magrini, 2008; Raful, Juchem, \& Cavalheiro, 2010; Oliveira, 2011; Deliberal, Cucchi, Tisott, \& Tondolo, 2013).

Para Oliveira e Serra (2010), a norma ISO 14001 baseia-se nos princípios de melhoria contínua e se utiliza de uma ferramenta de gestão de qualidade denominada ciclo PDCA, que se propõe a promover a melhoria contínua dos processos por meio de um circuito de quatros ações: planejar (plan) políticas, impactos e metas ambientais, executar (do) atividades ambientais e documentação ambiental, verificar (check) auditorias ambientais e avaliação de desempenho ambiental e agir (action) ) treinamento ambiental e comunicação ambiental. Com a implantação do ciclo PDSA as empresas buscam conformidade. O Compliance pode ser um sinalizador para o mercado.

A implantação do SGA nas empresas por meio da certificação NBR ISO 14001, embora seja importante para o aumento da competitividade das empresas no mercado nacional e internacional, é um processo que incorre em custos e tempo, o que pode ser um obstáculo para as empresas em arcar com esses gastos, em virtude do seu orçamento limitado e muitas vezes comprometido e da burocracia em obter recursos financeiros (Santos \& Seiffert, 2006). Com a implantação de um SGA as empresas podem reduzir custos, mitigar riscos e com isso atrais mais a atenção do mercado, que pode perceber sinalização de menor risco de longo prazo. Segundo Vieira Filho (2015), para que as empresas possam implantar o seu SGA, a captação de recursos financeiros é inevitável e quando esses recursos são provenientes de capitais de terceiros a empresa pode assumir novas dívidas. Neste sentido, Vieira Filho (2015) aponta possíveis determinantes para a estrutura do endividamento das empresas que são consideradas na análise no intuito de mitigar endogeneidade por ausência de variável relevante. Vieira Filho (2015) recomenda as seguintes variáveis que podem ser determinantes do endividamento das empresas dentre outros: tamanho da empresa, rentabilidade, tangibilidade dos ativos, dentre outros.

As hipóteses a serem testadas neste estudo são:

H1: existe relação entre a certificação ISO 14001 e o endividamento total das empresas.

H2: existe relação entre a certificação ISO 14001 e o endividamento longo prazo das empresas.

H3: existe relação entre a certificação ISO 14001 e o endividamento curto prazo das empresas.

\section{METODOLOGIA}

Trata-se esta pesquisa de um estudo empírico, que se utilizou de dados de acesso público numa análise longitudinal de dados das empresas listadas na B3.

3.1 Procedimentos Metodológicos

A operacionalização deste estudo tem o intuito de responder à questão da pesquisa no que diz respeito à relação do SGA e o endividamento das empresas. A verificação da relação da responsabilidade ambiental, por meio da certificação NBR ISO 14001:2004, com a capacidade de financiamento das empresas listadas na Bolsa de Valores - B3. Especificamente, pretende-se verificar o efeito da certificação NBR ISO 14001:2004 no endividamento total, no endividamento no curto prazo e no endividamento no longo prazo.

Para verificar esse efeito foram analisados os valores dos indicadores econômico-financeiros das empresas listadas na Bolsa de Valores - B3. Para a averiguação desses indicadores econômico-financeiros foram observados os índices de rentabilidade (ROA), A Estrutura/composição dos ativos (Tangibilidade), 
o tamanho da empresa (Ativo Total), a decisão da aplicação de recursos em longo prazo (Investimentos) e os estoques como fator potencial de geração de negócios e de lucros.

Nesse sentido, todas as empresas listadas na B3 participaram do estudo. O grupo de empresas certificadas foi chamado de grupo de tratamento, enquanto que o grupo de empresas não certificadas, foi chamado de grupo de controle. Foram eliminadas da amostra as empresas com PL Negativo. A exclusão das empresas com PL negativo é defendida por (Couson, 2009, Sun \& Cui, 2014, \& Mengze \& Wei, 2015). As empresas as empresas com PL negativo são excluídas naturalmente pelo mercado de crédito no processo de análise sobre a concessão de crédito por instituições financeiras (Couson, 2009, Sun \& Cui, 2014, \& Mengze \& Wei, 2015)

\subsection{Métodos estatísticos, modelo e variáveis}

O presente trabalho tem como principal foco responder se o endividamento da firma muda devido ao fato da empresa ter aderido ou não à certificação ISO 14001. Para se responder a tal questionamento, duas técnicas estatísticas principais foram executadas ao longo do trabalho:

(i) Teste de média para duas populações

(ii) Modelo econométrico de dif-in-dif (diferenças em diferenças)

Os testes de média para duas populações foram executados com o intuito de dar um primeiro resultado do tema. $O$ teste em questão se trata de averiguar se em média pode-se afirmar que existe uma diferença estatisticamente significativa entre o endividamento de firmas que aderiram e firmas que não aderiram à certificação ISO 14001.

A segunda técnica utilizada para averiguar o impacto da adoção da certificação ISO 14001 no nível de endividamento das firmas foi por meio do modelo econométrico dif-in-dif (diferenças em diferenças). Esta técnica consiste em criar duas variáveis dummies e interagí-las. A primeira variável dummy tem caráter de grupo, que aufere o fato de um certo ponto da amostra pertencer ou não a um certo grupo. Assim, divide-se a amostra em dois grupos, denominados grupos de tratamento e grupo de controle. Meyer (1995) aponta a importância de inserir grupos de controle nesta metodologia. O grupo de tratamento é o grupo que se deseja averiguar o efeito de um certo evento em alguma variável para este grupo, no caso, o grupo de tratamento é aquele que de alguma forma é afetado pelo evento que se deseja estudar. O grupo de controle é um grupo que não foi afetado por um certo evento, este grupo apesar de não ser o que se deseja estudar, ele é necessário para se fazer a comparação do grupo que foi afetado e o grupo que não foi afetado pelo evento em questão. A segunda dummy tem caráter temporal, que divide o tempo em dois, que é antes e depois do evento que afeta um certo grupo, chamado de grupo de tratamento. A necessidade de se incluir esta variável se mostra pela importância de medir o efeito de uma certa variável após um certo evento, neste caso a certificação. Por fim estas duas dummies (uma que representa o grupo e outra que representa o tempo) são interagidas.

Ao interagir as duas dummies em um modelo econométrico, foi possível dizer como que uma variável alavanca ou suaviza o efeito da outra, em outras palavras, se o fato de estar depois de um certo evento faz com que uma variável seja mais ou menos afetada pelo fato de estar no grupo de controle ou no grupo de tratamento. A necessidade de colocar grupo de controle fica expressa novamente pelo motivo que a variável averiguada pode já ter alguma tendência ao longo do tempo que não seria identificada se colocado apenas o grupo que é afetado pelo evento. Um pouco ainda mais que isso, se não for colocado um grupo de controle, pode-se chegar em interpretações equivocadas, às vezes assumindo que o grupo que foi afetado tem um certo impacto em uma variável que já tinha uma tendência de ocorrer independente do evento estudado. 
Para Freguete, Nossa e Funchal (2015), o modelo estatístico de diferenças-em-diferenças, quando utilizada em uma regressão em painel com duplo efeito fixo, melhor se adapta a estudos longitudinais com múltiplas variáveis cujas unidades se repetem ao longo dos cortes transversais.

Ao utilizar o método de diferença-em-diferenças, pode-se comparar a mudança nos resultados no grupo de tratamento antes e depois da certificação, com a mudança nos resultados no grupo de controle. Dessa forma consegue-se controlar todos os fatores não observados que podem afetar os grupos ao logo do tempo (Freguete et al., 2015).

Especificamente no caso do presente trabalho, pretende-se utilizar como corte temporal a implementação da ISO 14001 e como diferenciação entre grupos a separação entre empresas que aderiram e empresas que não aderiram.

O modelo diferença-em-diferenças estimado, pode ser especificado como um modelo de regressão linear com duplo efeito fixo.

Desta forma, pretende-se verificar por meio da certificação ISO 14001, qual a relação da responsabilidade social e ambiental com a capacidade de financiamento das empresas listadas na B3. Especificamente pretende-se verificar o efeito da certificação ISO 14001 no endividamento das empresas, conforme Equação 1.

Conforme Quadro 1, pode-se observar que a variável explicada endividamento é testada utilizando-se três proxies para endividamento: endividamento total, endividamento de curto prazo e endividamento de longo prazo.

$$
\begin{gathered}
\text { Endividamento }_{i t}=\beta_{\text {oit }}+\beta_{1} \text { ISOGRUPO }_{i t}+\beta_{2} \text { POSISO }_{\text {IT }}+\beta_{3} \text { PRIMEIRO ANO }_{i t}+\beta_{4} \text { ANOANTERIORISO } \\
\text { troles }_{i t}+\varepsilon_{i t}
\end{gathered}
$$

Em que:

\begin{tabular}{|c|c|c|c|}
\hline TIPO & Variável & Descrição & Referências \\
\hline \multirow{3}{*}{$\begin{array}{l}\frac{\pi}{0} \\
\frac{\tilde{J}}{\overline{0}} \\
\frac{0}{x}\end{array}$} & $\begin{array}{l}\text { endividamento total } \\
\text { dividido pelo ativo total }\end{array}$ & $\begin{array}{l}\text { Soma das contas: Fornecedores, } \\
\text { financiamentos e debêntures (curto e } \\
\text { longo prazo) dividido pelo ativo. }\end{array}$ & $\begin{array}{l}\text { Leandro, (2006); Perobelli e Famá } \\
\text { (2003). }\end{array}$ \\
\hline & $\begin{array}{l}\text { endividamento longo } \\
\text { prazo dividido pelo } \\
\text { ativo total }\end{array}$ & $\begin{array}{l}\text { Soma das contas: Fornecedores, } \\
\text { financiamentos e debêntures (longo } \\
\text { prazo) dividido pelo ativo. }\end{array}$ & $\begin{array}{l}\text { Leandro, (2006); Perobelli e Famá } \\
\text { (2003). }\end{array}$ \\
\hline & $\begin{array}{l}\text { endividamento curto } \\
\text { prazp dividido pelo } \\
\text { ativo total }\end{array}$ & $\begin{array}{l}\text { Soma das contas: Fornecedores, } \\
\text { financiamentos e debêntures (curto } \\
\text { prazo) dividido pelo ativo. }\end{array}$ & $\begin{array}{l}\text { Leandro, (2006); Perobelli e Famá } \\
\text { (2003). }\end{array}$ \\
\hline \multirow{4}{*}{ 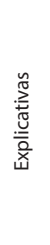 } & iso_grupoit & $\begin{array}{l}1 \text { se a empresa i já havia aderido à ISO } \\
14001 \text { no ano it e zero nos demais casos; }\end{array}$ & \\
\hline & Posisoit & $\begin{array}{l}1 \text { se a empresa estava certificada e zero } \\
\text { nos demais casos; }\end{array}$ & \\
\hline & primeiro anoit & $\begin{array}{l}1 \text { se o ano t for o ano em que a empresa } \\
\text { i aderiu à certificação ISO 14001; }\end{array}$ & \\
\hline & ano anterior_isoit & $\begin{array}{l}1 \text { se o ano t for o ano anterior ao que a } \\
\text { empresa } \mathrm{i} \text { aderiu e zero caso contrário. }\end{array}$ & \\
\hline \multirow{5}{*}{ 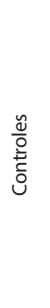 } & tamanho da empresa & Ln (Ativo Total da empresa) & $\begin{array}{l}\text { Rajan e Zingales (1995); Johnson } \\
\text { (1997); Houston e James (1996). }\end{array}$ \\
\hline & rentabilidade & $\begin{array}{l}\text { (Lucro operacional/ativo total da } \\
\text { empresa) }\end{array}$ & Rajan e Zingales (1995). \\
\hline & Imobilizado & $\begin{array}{l}\text { (Imobilizado líquido/Ativo total da } \\
\text { empresa) }\end{array}$ & $\begin{array}{l}\text { Rajan e Zingales (1995); Johnson } \\
\text { (1997). }\end{array}$ \\
\hline & Investimentos & $\begin{array}{l}\text { (Investimentos líquido/Ativo total da } \\
\text { empresa) }\end{array}$ & $\begin{array}{l}\text { Rajan e Zingales (1995); Johnson } \\
\text { (1997). }\end{array}$ \\
\hline & Estoques & $\begin{array}{l}\text { (Estoques líquido/Ativo total da } \\
\text { empresa) }\end{array}$ & $\begin{array}{c}\text { Rajan e Zingales (1995); Johnson } \\
\text { (1997). }\end{array}$ \\
\hline
\end{tabular}

Quadro 1: Descrição das Variáveis

Fonte: elaborado pelos autores 
Note que a primeira variável explicativa já representa o produto que foi referido no modelo diferenças em diferenças, uma vez que se trata das empresas que aderiram à norma e depois que a norma já estava em vigor.

A inclusão da variável PRIMEIRO ANOit e ANOANTERIOR_ISO it busca mensurar se o comportamento do endividamento é alterado quando a empresa acaba de aderir à norma, bem como se o fato de saber que no próximo ano irá aderir, muda também o comportamento.

controla o modelo pelo efeito fixo de empresa, enquanto controla pelo efeito fixo de ano. $\mathrm{O}$ coeficiente de maior interesse em toda a análise é o coeficiente , que é o coeficiente da interação entre a variável de grupo e de tempo. Dentre as variáveis de controle estão uma coleção de variáveis que podem exercer algum tipo de impacto no endividamento da firma, que foram vistas na literatura como:Tamanho da empresa, rentabilidade, tangibilidade do ativo, investimentos e estoque.

representa o termo de erro do modelo de regressão.

Para justificar as variáveis de controle do estudo, observou-se que em pesquisas realizados por Teixeira, Nossa e Funchal (2011) o tamanho da empresa está relacionado positivamente com o aumento da dívida, neste caso as maiores empresas tendem a ter maior endividamento, inclusive a custos menores, sendo considerado um indicador inverso para falência (Titman \&Wessels, 1988, Leandro, 2006; Antoniou, Guney, \& Paudyal, 2002; Perobelli \& Famá, 2003). A a rentabilidade (Lucratividade), mantém uma relação inversa com o endividamento (Myers, 1984; Harris \& Raviv, 1991). Em relação a estrutura e a composição dos ativos (tangibilidade), quanto maiores os ativos da empresa, menor foi o seu custo do endividamento, em função da possibilidade de usar esses tangíveis como garantias, por serem facilmente avaliados pelo mercado e mais propensos à relação de troca. Nesse sentido as empresas com maiores ativos podem estar mais propensas ao endividamento (Titman \& Wessels, 1988; Perobelli \& Famá, 2002, 2003).

\subsection{Coleta, seleção e tratamento de dados}

Foram selecionadas as empresas certificadas no período compreendido de outubro de 1996 (ano em que foi criada a Certificação NBR ISO 14001 no Brasil) a dezembro de 2016. Assim, para esta pesquisa a população foi definida como as empresaslistadas na B3, envolvendo tanto as empresas detentoras da certificação ISO 14001 quanto as as empresas que não são detentoras de Certificação. Os elementos econômico-financeiros foram levantados na base dados Economática.

Para o levantamento das empresas brasileiras certificadas, utilizaram-se como fontes o site do INMETRO, o site das empresas certificadas (ou recertificadas) e credenciadas por esse órgão. O cruzamento da lista de empresas constante na base do INMETRO, com aquelas constantes na base de dados Economática permitiu a identificação das empresas de capital aberto certificadas segundo o padrão NBR ISO 14001:2014, conforme Tabela 1:

TABELA 1: EMPRESAS COM CERTIFICAÇÃO NBR ISO 14001:2004

\begin{tabular}{|c|c|c|c|c|c|c|c|}
\hline \multicolumn{7}{|c|}{ Painel A - Distribuição das empresas certificadas ISO 14001 durante o período da amostra } \\
\hline Ano & $\begin{array}{c}\text { Empresas } \\
\text { Certificadas }\end{array}$ & Ano & $\begin{array}{c}\text { Empresas } \\
\text { Certificadas }\end{array}$ & Ano & $\begin{array}{c}\text { Empresas } \\
\text { Certificadas }\end{array}$ & Ano & $\begin{array}{c}\text { Empresas } \\
\text { Certificadas }\end{array}$ \\
\hline 1996 & 4 & 2002 & 38 & 2008 & 64 & 2014 & 86 \\
\hline 1997 & 8 & 2003 & 41 & 2009 & 70 & 2015 & 86 \\
\hline 1998 & 10 & 2004 & 47 & 2010 & 73 & 2016 & 86 \\
\hline 1999 & 18 & 2005 & 51 & 2011 & 76 & & \\
\hline
\end{tabular}

5 We used the Demo version of NAU platform available in <https://natural-language-understanding-demo.ng.bluemix.net/> 


\begin{tabular}{|l|l|l|l|l|l|l|l|}
\hline 2000 & 25 & 2006 & 58 & 2012 & 82 & & \\
\hline 2001 & 31 & 2007 & 59 & 2013 & 84 & & \\
\hline
\end{tabular}

Fonte: Os autores.

Por terem como características o endividamento como atividade-fim, e apresentarem contas nos demonstrativos financeiros diferentes dos demais grupos, foram excluídas da amostra instituições bancárias, seguradoras, instituições de créditos e outros fundos (Ferron et al., 2012). As instituições financeiras foram excluídas da amostra, pois são instituições que passam por forte regulação, de modo que o seu endividamento é regulado pelo Governo (Ferron et al., 2012). Outro motivo é que a conta estoque é uma das variáveis de controle e nesta conta há missing values para instituições financeiras. Desta forma, para não distorcer os resultados e por não se tratar de empresas foco deste estudo as Instituições financeiras foram excluídas do estudo.

Para verificar a significância estatística dos resultados, empregou-se o teste diferenças em diferenças.

Esta base de dados tem um total de 8.400 observações de 400 empresas, que foram reduzidas para 2.164 observações, por um período que vai de 1996 a 2016. Foram excluídas instituições bancárias, seguradoras, instituições de créditos e outros fundos. Os dados passaram por um processo de tratamento para correção de possíveis out-liers que poderiam conter na amostra. Para se fazer tal correção foi utilizada a técnica de winsorização, que consiste em substituir valores extremos pelos percentis selecionados. No caso do presente trabalho, foi considerado um percentil de 2,5, que significa que os valores extremos que estão nos últimos 2,5 percentis e nos 2,5 primeiros são substituídos pelo valor que está justamente em cima destes percentis. A vantagem da técnica de winsorização em relação à técnica de boxplot é o fato de não precisar eliminar observações.

\section{ANÁLISE DE RESULTADOS}

A Tabela 2 apresenta os resultados encontrados na estatística descritiva.

TABELA 2: ESTATISTIICA DESCRITIVA

\begin{tabular}{|c|c|c|c|c|c|c|c|c|c|}
\hline Variável & Média & $\begin{array}{c}\text { Desvio } \\
\text { padrão }\end{array}$ & Mínimo & Perc. 5 & $1^{\circ}$ quartil & Mediana & $3^{\circ}$ quartil & Perc.95 & Máximo \\
\hline dividalongoprazo & 0,292 & 0,179 & 0,000 & 0,000 & 0,140 & 0,299 & 0,422 & 0,590 & 0,658 \\
\hline dividacurtoprazo & 0,235 & 0,155 & 0,005 & 0,026 & 0,118 & 0,212 & 0,314 & 0,568 & 0,663 \\
\hline Dividatotal & 0,531 & 0,228 & 0,036 & 0,093 & 0,398 & 0,559 & 0,696 & 0,881 & 0,927 \\
\hline ROA & 0,064 & 0,093 & $-0,182$ & $-0,096$ & 0,015 & 0,061 & 0,113 & 0,227 & 0,310 \\
\hline Imobilizado & 0,221 & 0,239 & 0,000 & 0,000 & 0,008 & 0,142 & 0,367 & 0,716 & 0,813 \\
\hline Investimento & 0,103 & 0,241 & 0,000 & 0,000 & 0,000 & 0,001 & 0,038 & 0,815 & 0,913 \\
\hline Estoque & 0,067 & 0,088 & 0,000 & 0,000 & 0,000 & 0,010 & 0,124 & 0,259 & 0,303 \\
\hline Tamanho & 14,302 & 2,027 & 9,338 & 10,284 & 13,125 & 14,584 & 15,703 & 17,303 & 17,807 \\
\hline
\end{tabular}

Fonte: elaborado pelos autores.

Os resultados da estatística descritiva (Tabela 2) sugerem que em 22\% da amostra, a ISO 14001 já tinha sido implementada, que é representado pela média 0,22 da variável Pos_ISO. A dívida de longo prazo, em média representa $29,2 \%$ do ativo das empresas ao longo do ano, é possível afirmar que esta variável apresenta alto nível de dispersão, uma vez que seu desvio padrão representa mais de $60 \%$ da média. Outro indicativo deste resultado é a alta amplitude dos dados, que mostram que a diferença entre o maior e o menor nível de endividamento são de quase 66 pontos percentuais (Tabela 2). 
Na Tabela 2 ao analisar os dados percebe-se que as empresas mantêm em média um nível de endividamento de curto prazo percentualmente menor em comparação com o ativo, e este também se apresenta altamente volátil na amostra. Como a média é uma métrica linear, pode-se notar que a média do endividamento total é simplesmente a soma da média do endividamento de longo e curto prazo e apresenta uma dispersão de aproximadamente $43 \%$ da média. (Tabela 2)

Dentre as demais variáveis, que foram utilizadas como controles nas análises de regressão, vale destacar a variável ROA, que apresentou elevada dispersão, uma vez que o seu desvio padrão é superior à média (quase uma vez e meia), o que implica em um coeficiente de variação de quase 150\% (Tabela 2). Isso significa que a rentabilidade sobre o ativo tem alta variabilidade entre as empresas e entre os anos pesquisados, uma característica da amostra que ressalta isso é o fato de o mínimo ser de 18,1\% negativo e o máximo de $31 \%$ positivo, mostrando que a rentabilidade teve alta oscilação (Tabela 2).

Ainda analisando a Tabela 2, pode-se verificar que outra variável que apresentou uma anomalia evidente foi a variável de investimento em proporção ao ativo, que também apresentou altíssimo coeficiente de variação (234\%). E isso se deve ao fato de grande parte da amostra ter nível de investimento nulo. Note que a mediana é muito próxima de zero, o que significa que $50 \%$ ou mais da amostra não realizou investimento, ou fez um investimento ínfimo, enquanto que o percentil 95 foi de 0,85 , que indica que pelo menos $5 \%$ da amostra fez alto nível de investimento (pelo menos $85 \%$ do ativo), isso pode explicar a alta volatilidade dos dados. É importante ressaltar que apesar de algumas variáveis estarem altamente voláteis a amostra já foi winsorizada considerando nível de 2,5\% de corte nas caudas (Tabela 2).

Fez-se o teste de variância para duas populações e na sequência fez-se os testes de média. O resultado do teste de média ao comparar as empresas que aderiram e as que não aderiram à ISO 14001. Para os testes de média, considerando um nível de significância de até $10 \%$, pode-se afirmar que apenas dívida total e estoques que se mostram estatisticamente iguais entre os dois grupos. Os resultados do teste de média indicam, que todas as demais variáveis apresentaram diferença estatisticamente significativa entre os dois grupos.

Ao analisar o teste de média, por um lado, com relação às dívidas, pode-se afirmar com $5 \%$ de significância a dívida de longo prazo é estatisticamente maior para a amostra de empresas que aderiram a norma depois da adoção da norma. Por outro lado, a dívida de curto prazo se mostrou estatisticamente maior na amostra antes da adoção da ISO 14001

Os Resultados do teste de média sugerem que uma maior responsabilidade nos processos por parte da empresa, que vem da adesão da norma, pode resultar em maior capacidade de financiamento de longo prazo, o que pode ser explicado pelo aumento de confiança que as instituições financeiras imprimem a respeito destas empresas. Ainda conforme resultados do teste de média, pode-se dizer que estas empresas puderam fazer uma substituição de financiamentos de curto prazo por financiamentos de longo prazo, o que também estaria diretamente associado à confiança imposta pela adoção da norma

Quanto às demais variáveis, pode-se dizer que ROA, investimento e In_ativo são em média maiores depois que as empresas aderem à ISO 14001 do que quando ainda não haviam aderido, o que também pode estar inerente a uma maior confiança depositada nessas empresas depois da adesão, que permitem maiores investimentos, crescimento da rentabilidade dos ativos. E por fim o teste de média traz indícios de que o imobilizado apresenta média estatisticamente maior para as empresas antes de aderirem à norma do que quando comparado às mesmas empresas após a adesão da norma. Além disso, pode-se afirmar que não existe diferença estatisticamente significativa entre os estoques médios quando feita uma comparação de antes e depois de aderirem à ISO 14001. 
Antes de estimar o modelo de regressão usando o modelo dif-in-dif, foi feita uma matriz de correlação entre as principais variáveis. A matriz de correlação apresenta nível de correlação das variáveis que não compromete a estimação da relação estudada. Na sequência das análises, foi realizada o teste de regressão dif in dif, com três métricas de endividamento, dívidas de curto prazo, longo prazo e total, nas quais são acrescentadas dummies de período (antes e depois do início da ISO 14001) e dummies de tempo que controlam se a empresa estava no ano em que foi adotada a norma bem como uma dummy que representa o fato de a empresa estar em um ano antes de implementar a ISO ou não.

Na Tabela 3 são apresentados os resultados encontrados nos modelos de regressão, na qual a variável explicada é a dívida total dividida pelo ativo total. Na especificação 1 há somente a variável explicada ISOGRUPO. Na especificação 2 é adicionada a variável POSISO e na especificação 3 é incluída também a variável ANO ANTERIOR ISO. Isso ocorre nas estimações apresentadas nas Tabelas 3 (endividamento total), Tabela 4 (endividamento longo prazo) e Tabela 5 (endividamento curto prazo).

TABELA 3: ANÁLISE DE REGRESSÃO - MODELO DIF IN DIF.

\begin{tabular}{|c|c|c|c|c|c|c|}
\hline \multicolumn{7}{|c|}{ 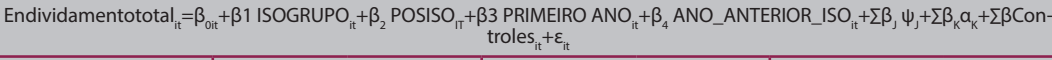 } \\
\hline & \multicolumn{2}{|c|}{ Especificação 1} & \multicolumn{2}{|c|}{ Especificação 2} & \multicolumn{2}{|c|}{ Especificação 3} \\
\hline Variáveis & Coef. & $\mathrm{t}$ & Coef. & $\mathrm{t}$ & Coef. & $\mathrm{t}$ \\
\hline \multicolumn{7}{|l|}{ Variável Dependente: } \\
\hline \multicolumn{7}{|l|}{ Endividamento total } \\
\hline ISOGrupo & $-0,01895^{*}$ & $-1,83$ & $-0,0255152$ & $-0,83$ & $-0,0053826$ & $-0,12$ \\
\hline Roa & $-0,18288^{* * *}$ & $-3,41$ & $-0,1832656^{* * *}$ & $-3,42$ & $-0,1822104^{* * *}$ & $-3,39$ \\
\hline Imobilizado & $0,03569^{*}$ & 1,76 & $0,0359245^{*}$ & 1,77 & $0,0358704^{*}$ & 1,77 \\
\hline Investimento & $-0,27959^{* * *}$ & $-12,24$ & $-0,279638^{* * *}$ & $-12,24$ & $-0,27977^{* * *}$ & $-12,24$ \\
\hline Estoques & $0,14998^{* * *}$ & 3,03 & $0,1500808^{* * *}$ & 3,03 & $0,150452^{* * *}$ & 3,04 \\
\hline Tamanho & $0,29978^{* * *}$ & 10,79 & $0,0299497^{* * *}$ & 10,74 & $0,0299241^{* * *}$ & 10,73 \\
\hline Crise & $-0,03628$ & $-0,35$ & $-0,0363349$ & $-0,35$ & $-0,0363628$ & $-0,35$ \\
\hline Pos_ISO & - & - & 0,0070647 & 0,23 & $-0,0113511$ & $-0,26$ \\
\hline Primeiro_Ano & - & - & & & $-0,0109585$ & $-0,51$ \\
\hline Ano_Anterior_ISO & - & - & & & $-0,0413909$ & $-0,7$ \\
\hline Constant & $0,12947^{* * *}$ & 3,01 & $0,1298457^{* * *}$ & 3,01 & 0,1301402 & 3,02 \\
\hline $\mathrm{R}^{2}$ & 0,1957 & & 0,1957 & & 0,1957 & \\
\hline Observações & 2164 & & 2164 & & 2164 & \\
\hline
\end{tabular}

Fonte: elaboração própria pelos autores

Legenda: Os coeficientes que apresentam três asteriscos $\left(^{* * *}\right)$ são estatisticamente significativas considerando um nível de $1 \%$ de significância, com dois asteriscos $\left(^{* *}\right)$, significativo à $5 \%$ de significância e com um asterisco (*), significativo com 10\% de significância.

Na Tabela 3 é representado o modelo de regressão quando analisada a variável dependente de dívida total, a variável ISOGrupo se mostra estatisticamente significativo apenas na primeira especificação. O coeficiente apresentou sinal negativo, o que indica que em média, o fato de uma empresa adotar a norma faz com que sua dívida total diminua.

Todos os controles em comum entre os três modelos se mostraram estatisticamente significativos, com exceção à crise, o que indica por exemplo que empresas que possuem maior ativo imobilizado, menor nível de investimento, estoques e ativos maiores, em média apresentam uma maior capacidade de realizar financiamentos de forma geral. A variável crise não foi estatisticamente significativa em nenhuma 
especificação, indicando que em média, em época de crise se tem o mesmo nível de endividamento total quando comparado ao cenário sem crise (Tabela 3).

Tanto na segunda quanto na terceira especificação, a variável temporal POSISO não foi estatisticamente significativa, indicando que em média, a partir do momento da implementação da ISO 14001 não se tem variação da capacidade de financiamento por parte das empresas. A dummies de tempo (se está no período da adoção ou não bem como se está em um ano anterior ou não) não se apresentaram estatisticamente significativas, indicando que em média, no ano da adoção e no ano anterior, se toma o mesmo nível de dívida do que no geral (Tabelas 4 e 5 )

TABELA 4: ANÁLISE DE REGRESSÃO - MODELO DIFIN DIF

\begin{tabular}{|c|c|c|c|c|c|c|}
\hline \multicolumn{7}{|c|}{ 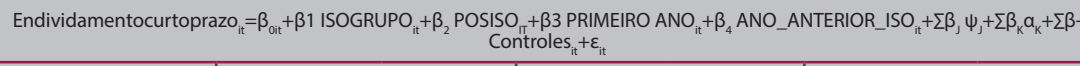 } \\
\hline \multirow[b]{2}{*}{ Variáveis } & \multicolumn{2}{|c|}{ Especificação 1} & \multicolumn{2}{|c|}{ Especificação 2} & \multicolumn{2}{|c|}{ Especificação 3} \\
\hline & Coef. & $t$ & Coef. & $\mathrm{t}$ & Coef. & $\mathrm{t}$ \\
\hline \multicolumn{7}{|l|}{$\begin{array}{l}\text { Variável Dependente: } \\
\text { endividamento curto } \\
\text { prazo }\end{array}$} \\
\hline ISO_Grupo & $-0,0151366^{* *}$ & $-2,37$ & 0,0188868 & 0,77 & $0,0257877^{* * *}$ & 3,42 \\
\hline Roa & 0,037756 & 0,99 & 0,039737 & 1,04 & $0,0479586^{* * *}$ & 2,6 \\
\hline Imobilizado & $-0,079873^{* * *}$ & $-5,92$ & $-0,081086^{* * *}$ & $-6,01$ & $-0,0357724^{* * *}$ & $-5,27$ \\
\hline Investimento & $-0,211258^{* * *}$ & $-19,7$ & $-0,21103^{* * *}$ & $-19,68$ & $-0,215161^{* * *}$ & $-26,28$ \\
\hline Estoques & $0,553432^{* * *}$ & 14,47 & $0,5529177^{* * *}$ & 14,44 & $0,6425272^{* * *}$ & 32,77 \\
\hline Tamanho & 0,0012824 & 0,73 & 0,0014295 & 0,81 & $0,0065932^{* * *}$ & 7,55 \\
\hline Crise & $-0,0203906$ & $-0,5$ & $-0,0200948$ & $-0,49$ & $-0,0137974^{*}$ & $-1,93$ \\
\hline Pos_ISO & - & - & $-0,0366181$ & $-1,48$ & $-0,0507906^{* * *}$ & $-6,1$ \\
\hline Primeiro_Ano & - & - & - & - & $0,0267716^{* *}$ & 2,11 \\
\hline Ano_Anterior_ISO & - & - & - & - & $-0,0312006^{* *}$ & $-2,17$ \\
\hline Constant & $0,2199623^{* * *}$ & 7,97 & $0,2180332^{* * *}$ & 7,89 & $0,1359219^{* * *}$ & 11,23 \\
\hline $\mathrm{R}^{2}$ & 0,2467 & & 0,2476 & & 0,2479 & \\
\hline Observações & 2164 & & 2164 & & 2164 & \\
\hline
\end{tabular}

Fonte: elaboração própria pelos autores

Legenda: Legenda: Os coeficientes que apresentam três asteriscos $\left(^{* * *}\right)$ são estatisticamente significativas considerando um nível de $1 \%$ de significância, com dois asteriscos $(* *)$, significativo à $5 \%$ de significância e com um asterisco $(*)$, significativo com 10\% de significância,

Ao analisar a Tabela 4, se tem agora como variável dependente os modelos de dívida de curto prazo. O resultado difere um pouco no que tange a variável ISOGrupo. Note que agora a variável ISOGrupo se apresenta estatisticamente significativa na primeira e na terceira especificação e com sinais contrários. Na primeira especificação o sinal é negativo, que indica que em média a dívida de curto prazo é reduzida quando as empresas aderem a norma, esse sinal, porém, se inverte quando adicionadas as outras variáveis (pos_iso, primeiro_ano, ano_anterior iso), o que indicaria que a adoção da norma na verdade aumentaria o endividamento (Especificação 3) de curto prazo. Na primeira especificação, uma possível interpretação é que quando a empresa apresenta maior responsabilidade, poder fazer escolhas entre financiamento de curto e de longo prazo e talvez optando pelo de longo prazo. (Tabelas 4 e 5). 
TABELA 5: ANÁLISE DE REGRESSÃO - MODELO DIFIN DIF.

\begin{tabular}{|c|c|c|c|c|c|c|}
\hline & \multicolumn{2}{|c|}{ Especificação 1} & \multicolumn{2}{|c|}{ Especificação 2} & \multicolumn{2}{|c|}{ Especificação 3} \\
\hline Variáveis & Coef. & $t$ & Coef. & $\mathrm{t}$ & Coef. & $\mathrm{t}$ \\
\hline $\begin{array}{l}\text { Variável Dependente } \\
\text { endidividamento de } \\
\text { longo prazo }\end{array}$ & & & & & & \\
\hline ISO_Grupo & $-0,0055414$ & $-0,65$ & $-0,0505837^{* *}$ & $-1,98$ & 0,0401779 & 1 \\
\hline Roa & $-0,205962^{* * *}$ & $-4,77$ & $-0,208584^{* * *}$ & $-4,83$ & 0,0403167 & 1,05 \\
\hline Imobilizado & $0,1195158^{* * *}$ & 7,67 & $0,1211214^{* * *}$ & 7,79 & $-0,081205^{* * *}$ & $-6,02$ \\
\hline Investimento & $-0,070782^{* * *}$ & $-3,67$ & $-0,071087^{* * *}$ & $-3,69$ & $-0,2112^{* * *}$ & $-19,68$ \\
\hline Estoques & $-0,391419^{* * *}$ & $-9,98$ & $-0,390738^{* * *}$ & $-9,97$ & $0,5532305^{* * *}$ & 14,45 \\
\hline Tamanho & $0,0305635^{* * *}$ & 13,63 & $0,0303687^{* * *}$ & 13,5 & 0,0014192 & 0,8 \\
\hline Crise & $-0,0121041$ & $-0,13$ & $-0,0124956$ & $-0,14$ & $-0,0200934$ & $-0,49$ \\
\hline Pos_ISO & - & - & $0,0484774 *$ & 1,86 & $-0,0568958$ & $-1,41$ \\
\hline Primeiro_Ano & - & - & - & - & $-0,006474$ & $-0,52$ \\
\hline Ano_Anterior_ISO & - & - & - & - & $-0,0437761$ & $-0,94$ \\
\hline Constant & $-0.123709 * * *$ & $-3,65$ & $-0,121156$ & $-3,57$ & $0,218156^{* * *}$ & 7,89 \\
\hline$R^{2}$ & 0,2052 & & 0,2063 & & 0,2479 & \\
\hline Observaçōes & 2164 & & 2164 & & 2164 & \\
\hline
\end{tabular}

Fonte: elaboração própria pelos autores

Legenda: Legenda: Os coeficientes que apresentam três asteriscos $\left(^{* * *}\right)$ são estatisticamente significativas considerando um nível de $1 \%$ de significância, com dois asteriscos $(* *)$, significativo à $5 \%$ de significância e com um asterisco $(*)$, significativo com $10 \%$ de significância.

Na Tabela 5, se tem como variável dependente a dívida de longo prazo. Dessa vez a variável que representa o fato de uma empresa ter aderido ou não à norma apresenta coeficiente estatisticamente significativo apenas na segunda especificação e este se apresenta negativo, o que significa que em média, o fato de uma empresa aderir à norma faz com que a sua capacidade de financiamento de longo prazo diminua.

Os resultados não se mostram consistentes em relação às dummies de ano da adoção e ano anterior, uma vez que esses não são estatisticamente significativos nessas especificações (Tabela 5). Ao comparar os resultados das Tabelas 4 e 5 é possível observar que: apesar de no segundo painel apenas uma especificação apresentar sinal negativo no coeficiente de ISOGrupo, pode-se notar que tem uma maior tendência de aumento de financiamento de longo prazo e de redução de financiamento de curto prazo, como se a responsabilidade que é auferida ao adotar a norma, desse às empresas a possibilidade de substituição de financiamentos de curto por financiamentos de longo prazo.

\section{CONCLUSÃO}

O estudo teve como objetivo principal verificar a relação da implantação do SGA (NBR ISO 14001:2004) com o endividamento das empresas brasileiras, com ações negociadas na B3.

Em resposta ao questionamento utilizou duas técnicas estatísticas: teste de média de duas populações e teste do modelo econométrico de dif-in-dif (diferenças em diferenças). $O$ teste de médio era para averiguar se em média existe uma diferença estatisticamente significativa no endividamento do grupo de empresas que aderiram e do grupo de empresas que não aderiram à certificação. E a segunda técnica análise de regressão em diferenças em diferenças foi para averiguar a relação da adoção da certificação 
ISO 14001:2004 com o endividamento das empresas. Os resultados encontrados limitam-se a análise das amostras, do período compreendido e testado, nos modelos propostos, haja vista que muitos são os potencias determinantes do endividamento a curto, longo prazo e no endividamento total.

Os resultados encontrados por meio da técnica diferenças em diferenças com base na análise de regressão aponta que existe uma maior evidência de ISO 14.001 afetar o endividamento de forma negativa, ou seja, há uma redução de endividamento das empresas certificadas, de forma geral se comparadas às empresas não certificadas. As empresas certificadas reduziram o endividamento de curto prazo, mas ampliando o financiamento de longo prazo e isso pode estar resultando em substituição de financiamento de curto prazo por financiamento de longo prazo, o que pode ser resultado de um aumento de confiança devido à adesão à norma ISO 14001.

Com base na literatura apresentada, as empresas que possuem certificação do seu SGA, por meio da certificação NBR ISO 14001:2004 possuem um perfil destacado, que podem atrair a atenção de órgãos reguladores, de ambientalistas, de fornecedores, do governo, melhorando assim, o desempenho mercadológico dos seus produtos e serviços junto aos seus clientes. Nesse sentido, com base nos resultados encontrados nesta pesquisa intui-se que a adesão da norma é positiva para as empresas em linha com os argumentos de Cellier e Chollet (2016), Barros, Silva e Voese (2015) e Song, Zhao e Zeng (2017), de que o SGA melhora as condições financeiras das empresas de forma atraindo mais dívida de longo prazo. Uma vez que o financiamento de longo prazo é um sinal de que o mercado tem mais confiança nas empresas, então a relação positiva da certificação e o endividamento de longo prazo pode ser um indício de sinalização positiva das empresas após a certificação para o mercado. Dante dos resultados encontrados neste estudo, sugere-se que em futuras pesquisas seja analisado o efeito do Compliance da cerificação ISO 14001 no custo de capital das empresas.

\section{REFERÊNCIAS}

Alberton, A., \& Costa Jr, N. C. A. D. (2007). Meio ambiente e desempenho econômico-financeiro: benefícios dos Sistemas de Gestão Ambiental (SGAs) e o impacto da ISO 14001 nas empresas brasileiras. RAC-Eletrônica, 1(2), 153-171.

Antoniou, A., Guney, Y., \& Paudyal, K. (2002). Te determinants of corporate debt maturity structure. Anais do Annual Conference Paper n.802 - EFMA 2003 Helsinki Meetings.

Barbosa, G. S. (2008). O desafio do desenvolvimento sustentável. Revista Visões, 4(1), 1-11.

Barros, C. M. E., da Silva, P. Y. C., \& Voese, S. B. (2015). Relação entre o custo da dívida de financiamentos e governança corporativa no Brasil. Contabilidade, Gestão e Governança, 18(2).

BMF\&BOVESPA - Bolsa de Valores, Mercadorias e Futuros de São Paulo. Novo Mercado. Recuperado em 8 fevereiro, 2017, de http://www.bmfbovespa.com.br/pt-br/servicos/solucões-paraempresas/ segmentos-de-listagem/novo-mercado. aspx? idioma=pt-br.

Cellier, A., \& Chollet, P. (2016). The effects of social ratings on firm value. Research in International Business and Finance, 36, 656-683, doi: 10.1016/j.ribaf.2015.05.001

Christmann, P. (2000). Effects of "best practices" of environmental management on cost advantage: The role of complementary assets. Academy of Management journal, 43(4), 663-680. DOI: 10.2307/1556360

Coulson, A. B. (2009). Business Strategy \& the Environment (John Wiley \& Sons, Inc). 18(3), 149-161, doi: $10.1002 /$ bse.584

Dal Magro, C.B., Di Domenico, D., Utzig, M. J.S., Lavarda, C. E.F., \& Mazzioni, S. (2012). Responsabilidade Social nas Empresas Listadas na BM\&FBOVESPA. Gestão \& Planejamento-G\&P, 13(3), 746-765. 
DAMASCENO, Felipe Storch. (2019). Essays on information disclosure: impairment theory, trade credit and voluntary disclosure behavior. Tese (Doutorado em Ciências Contábeis e Administração) - Programa de Pós-Graduação em Ciências Contábeis e Administração, Fundação Instituto Capixaba de Pesquisas em Contabilidade, Economia e Finanças (FUCAPE), Vitoria, 2019.Deliberal, J. P., Cucchi, M. B., Tisott, P. B., \& Tondolo, V. A. G. (2013). Gestão ambiental como ferramenta para o aumento da competitividade e desempenho econômico. Tekhne e Logos, 4(3), 17-29.

El Ghoul, S., Guedhami, O., Kwok, C. C., \& Mishra, D. R. (2011). Does corporate social responsibility affect the cost of capital?. Journal of Banking \& Finance, 35(9), 2388-2406, doi: 10.1016/j.jbankfin.2011.02.007 Erragragui, E. (2017). Do creditors price firms' environmental, social and governance risks?. Research in International Business and Finance. 45(c) (197-207, doi: 10.1016/j.ribaf.2017.07.151

Faroni, W., Silveira, S. D. F.R, Magalhães, E. A. D., \& Magalhães, E. M. D. (2010). A contabilidade ambiental em empresas certificadas pelas normas ISO 14001 na região metropolitana de Belo Horizonte-MG. Revista Árvore, 34(6), 1119-1128. DOI: 10.1590/S0100-67622010000600018

Ferron, R. T., Funchal, B., Nossa, V., \& Teixeira, A. J. (2012). Is ISO 14001 certification effective?: an experimental analysis of firm profitability. BAR-Brazilian Administration Review, 9(SPE), 78-94. DOI: http://dx.doi. org/10.1590/S1807-76922012000500006

França, C. J., Nossa, V., Nossa, S. N., \& Funchal, B. (2015). Efeito Heterogêneo da ISO 14001 no Retorno Anormal. Revista Universo Contábil, 11(4), 63-81, 2015. DOI: 10.4270/ruc.2015432.

Freguete, L.M., Nossa, V., \& Funchal, B. (2015). Responsabilidade social corporativa e desempenho financeiro das empresas brasileiras na crise de 2008. RAC-Revista de Administração Contemporânea, 19(2), 232-248, 2015. DOI: 10.1590/1982-7849rac20151873

Gibson, K., \& Tierney, J. M. (2011). The evolution of environmental management systems: Back to basics. Environmental Quality Management, 21(1), 23-37. DOI: 10.1002/tqem.20306

Harris, M., \& Raviv, A. (1991). The theory of capital structure. the Journal of Finance, 46(1), 297-355. DOI: 10.1111/j.1540-6261.1991.tb03753.x

Heras-Saizarbitoria, I., Molina-Azorín, J. F., \& Dick, G. P. (2011). ISO 14001 certification and financial performance: selection-effect versus treatment-effect. Journal of Cleaner Production, 19(1), 1-12, doi: 10.1016/j.jclepro.2010.09.002

Hikichi, S. E., Salgado, E. G., \& Beijo, L. A. (2016). Análise do nível de intensidade de certificações no padrão ISO 14001: tendências para o continente americano. Desenvolvimento e Meio Ambiente, 38, 769-785, 2016. DOI: 10.5380/dma.v38i0.44927

Johnson, S. A. An empirical analysis of the determinants of corporate debt ownership structure. Journal of Financial and Quantitative Analysis, v. 32, n. 1, p. 47-69, 1997. DOI: 10.2307/2331316

Leandro, J. C. (2006). Determinantes da estrutura de capital no Brasil para empresas de capital aberto e fechado. Dissertação (Mestrado) - Escola de Administração de Empresas de São Paulo da Fundação Getúlio Vargas, São Paulo, Brasil.

Lemer, V. P. (2015). Panorama da certificação ISO 14001 em empresas no Estado do Paraná. Trabalho de Conclusão de Curso (Graduação em Engenharia Ambiental). Universidade Tecnológica Federal do Paraná. Matuszak-Flejszman, A. 2009. Benefits of Environmental Management System in Polish Companies Compliant with ISO 14001. Polish Journal of Environmental Studies, 18(3): 411-419.

Mazzioni, S., Tinoco, J. E. P., \& Oliveira, A. B. S. (2007). Proposta de um modelo de balanço social para fundações universitárias. BASE: Revista de Administração e Contabilidade da Unisinos, São Leopoldo, 4(3), 274-285.

Mengze, H., \& Wei, L. (2015). A Comparative Study on Environment Credit Risk Management of Commercial Banks in the Asia-Pacific Region. Business Strategy and the Environment, 24(3), 159-174, doi: 10.1002/bse.1810

Meyer, B. D. (1995). Natural and quasi-experiments in economics. Journal of Business \& Economic Statistics, 13(2), 151-161, DOI: 10.2307/1392369 
Moreira, M. S. (2006). Estratégia e Implantação do Sistema de Gestão Ambiental (Modelo ISO 14000). Nova Lima: INDG Tecnologia e Serviços Ltda.

Moura, A. A. F., Nascimento, F. S. P., \& Luca, M. M. M. (2010). Evidenciação voluntária de informações sociais por empresas de capital aberto sediadas nas regiões Norte, Nordeste, Centro-Oeste e Sudeste do Brasil: um estudo com base nos indicadores de responsabilidade social corporativa da ONU. Anais do Congresso Brasileiro de Custos, Belo Horizonte, BH, Brasil, 17.

Myers, S. C. (1984). The capital structure puzzle. The journal of finance, 39(3), 574-592, DOI: https://doi. org/10.1111/j.1540-6261.1984.tb03646.x

Nunes, E. (1997). A gramática política do Brasil - clientelismo e insulamento burocrático (3a ed.). Jorge Zahar: Rio de Janeiro; ENAP: Brasília.

Oliveira, J.A. (2011). Um estudo sobre a relação do sistema de gestão ambiental ISO 14001 com a adoção de procedimentos de produção mais limpa em empresas industriais brasileiras. 178 f. Dissertação (Mestrado em Engenharia de Produção) - Faculdade de Engenharia de Bauru, Universidade Estadual Paulista "Júlio de Mesquita Filho", Bauru.

Oliveira, O.J., \& Serra, J.R. (2010). Benefícios e dificuldades da gestão ambiental com base na ISO 14001 em empresas industriais de São Paulo. Produção, 20(3), 429-438, DOI: 10.1590/S0103-65132010005000013.

Oliveira, O. J., \& Pinheiro, C. R. M. S. (2009). Best practices for the implantation of ISO 14001 norms: a study of change management in two industrial companies in the Midwest region of the state of São Paulo, Brazil. Journal of Cleaner Production, 17(9), 883-885, DOI: 10.1016/j.jclepro.2008.12.008

Perobelli, F., \& Famá, R. (2003). Determinantes da estrutura de capital: aplicação a empresas de capital aberto brasileiras. Revista de Administração, 37(3).

Pombo, F. R., \& Magrini, A. (2008). Panorama de aplicação da norma ISO 14001 no Brasil. Revista Gestão e Produção, 15(1), 1-10. Doi: http://dx.doi.org/10.1590/S0104-530X2008000100002.

Raful, N. F., Juchem, D. M., \& Cavalheiro, M. E. (2010). Gestão Ambiental como diferencial competitivo empresarial. Revista Gestão Industrial, Ponta Grossa, 6(2),126-141. DOI: 10.3895/S1808-04482010000200007

Rajan, R. G.; Zingales, Luigi. What do we know about capital structure? Some evidence from international data. The Journal of Finance, 50(5), 1421-1460, 1995. DOI: https://doi.org/10.1111/j.1540-6261.1995. tb05184.x

Ramos, F. B., Álvares, I. M., Souza, M. T. S. de, \& Pereira, R. S. (2006). Certificação ISO 14000: Análise do Sistema de Gestão Ambiental da Ford Motor Company. RAI - Revista de Administração e Inovação, São Paulo, 3(2), 62-82.

Rao, P., \& Holt, D. (2005). Do green supply chains lead to competitiveness and economic performance? International Journal of Operations \& Production Management, 25(9/10), 898. DOI 10.1108/01443570510613956

Santos, D. S., \& Seiffert, M. E. (2006). Certificação ISO 14001: contribuições para a análise benefício /custo do processo. Anais do Encontro de Iniciação Científica, São José dos Campos, SP, Brasil, 6.

Sharfman, M. P., \& Fernando, C. S. (2008). Environmental risk management and the cost of capital. Strategic management journal, 29(6), 569-592, doi: https://doi.org/10.1002/smj.678

Shan, M., You, J., Wang, Y., \& Liu, H. (2015). A Process Model of Building Sustainable Competitive Advantage for Multinational Enterprises: An Empirical Case Study. (2015). Problemy Ekorozwoju - Problems of Sustainable Development, 10(1), 67-78.

Stefan, A., \& Paul, L. (2008). Does it pay to be green? A systematic overview. The Academy of Management Perspectives, 22(4), 45-62, doi: 10.5465/AMP.2008.35590353.

Song, H., Zhao, C., \& Zeng, J. (2017). Can environmental management improve financial performance: An empirical study of A-shares listed companies in China. Journal of cleaner production, 141, 1051-1056, doi: 10.1016/j.jclepro.2016.09.105 
Sun, W., \& Cui, K. (2014). Linking corporate social responsibility to firm default risk. European Management Journal, 32(2), 275-287, doi: 10.1016/j.emj.2013.04.003

Teixeira, E. A., Nossa, V., \& Funchal, B. (2011). O Índice de Sustentabilidade Empresarial (ISE) e os impactos no endividamento e na percepção de risco. Revista Contabilidade \& Finanças - USP, 22(55), 29-44. DOI: https://doi.org/10.1590/S1519-70772011000100003

Titman, S., \& Wessels, R. (1988). The determinants of capital structure choice. Journal of Finance, 43(1), 1-19. DOI: https://doi.org/10.1111/j.1540-6261.1988.tb02585.x

Vasi, I. B., \& King, B. G. (2012). Social movements, risk perceptions, and economic outcomes: The effect of primary and secondary stakeholder activism on firms' perceived environmental risk and financial performance. American Sociological Review, 77(4), 573-596, doi: 10.1177/0003122412448796

Vieira Filho, C. J. (2015). Determinantes da estrutura de dívidas das empresas brasileiras. Dissertação apresentada ao Programa de Pós-graduação em Administração de Empresas, Fundação Instituto Capixaba de Pesquisas em Contabilidade, Economia e Finanças - FUCAPE.

Zhu, Q., Cordeiro, J., Sarkis, J. (2013). Institutional pressures, dynamic capabilities and environmental management systems: Investigating the ISO 9000 - environmental management system implementation linkage. Journal of Environmental Management, 114: 232-242, DOI: 10.1016/j.jenvman.2012.10.006

\section{Como referenciar}

Costa, E. M. da.; Nossa, V.; Nossa, S. N.; Borgerth, V. M. da C. (2019). A Certificação ISO 14001 e o endividamento das Empresas Brasileiras. Advances in Scientific and Applied Accounting, 12(3), Set. / Dez. p. 159-176. 